\title{
Expanding Growth Pole and Thriving SEZ in the Bengal Gems and Jewellery Industry
}

\author{
Sri SukantaSaha*
}

\section{Abstract}

The present study focuses on two specific sites of the Gems and Jewellery industry in West Bengal, namely Domjur (Howrah) and Manikanchan (Rajarhat, Kolkata). Domjur Gems and Jewellery industry is the sole 'Growth Pole' in West Bengal including Panchla Zari and Embroidery industry. On the other hand, Manikanchan is the sole Special Economic Zone in the Gems and Jewellery industry in India. While Manikanchan, is thriving, Domjur is flourishing. The present study aims to search the reasons in the context of classical and neo-classical Location Economics literature. The study objects to detect factors responsible for thriving Manikanchan and expanding Domjur despite the fact that Manikanchan is a government-sponsored SEZ accruing all kinds of government support to promote exports. Domjur, on the other hand, is flourishing with participation of private enterprises. The study, therefore, attempts to explore the logic behind this paradoxical result. The logical argumentation of the study is based on literature support, case studies conducted, and primary survey results.

* Faculty, Department of Economics, Umeschandra College, Kolkata, West Bengal, India; ssesukanto@gmail.com 
The micro-level field surveys, sampling design and data analysis is based on standard model approach in order to accept spatial heterogeneity.

Keywords: Informal sector, Cluster economy, Economies of scale, Location, Mobility.

JEL Classification: E26, F02, J61, R10, R12.

\section{Introduction}

The present paper attempts to focus on two important spatial clusters $^{i}$ of the Gems and Jewellery industry in West Bengal, namely Domjur (Howrah) and Manikanchan (Rajarhat, Kolkata). The two sites have been selected because of their specific characteristics.ii Domjur Gold and Jewellery industry of Howrah district is the sole Growth Poleiii in West Bengal including Panchla Zari and Embroidery industry. The reference of Domjur is attributed to the 'Growth Pole' programme of the Central Government and in the Arjun Sengupta Report (2006). Manikanchan is the sole Special Economic Zone of the Gems and Jewellery industry in India. While Manikanchan is thriving despite several kinds of government support, Domjur is flourishing with increasing number of private (formal and informal) enterprises' participation. The present study, therefore, aims to explore the reasons behind this paradoxical phenomenon. The study objects to detect the factors that determine successful spread of localized agglomeration $^{\text {iv }}$ formation in one site but not in the other. The study further considers whether such a spatial concentration ${ }^{v}$ of production units is becoming cost-effective in a particular site and not in the other. The consideration is strongly based upon the support of literature derived from classical and new economic geography school of Location Economics vi and is verified on the basis of field surveys and case studies conducted.

\section{Methodology of Analysis}

The logical argumentation of the study is based on literature support, case studies and primary survey results. The literature support is based upon the classical and new economic geography school. The survey process is exhaustive. The survey is based on 
qualitative purposive sampling with semi-structured questionnaire and indirect interview method. The micro-level field studies, sampling design and data analysis are based on the standard model approach. The implication is that the selection of any sampling region does not depend on data availability (or nonavailability), hence avoids spatial homogeneity. The study also assumes that the producing firms within a particular cluster of the industry are non-homogeneous in nature. However, the spatial distribution of production units of a single industry is crosssectional, given and known. Sometimes an ethnographic study has been approached due to data non-availability and data nonresponses in the sample survey area under the purview of the study.

\section{The Industry Profile}

Manikanchan SEZ:In our study, the case of Manikanchan has been incorporated as a special instance. This sole Gems and Jewellery Special Economic Zone (SEZ) of the country is situated in Rajarhat, Kolkata, West Bengal. It started its operation since 2006. This SEZ functions as an offshore unit with several financial and nonfinancial benefits.

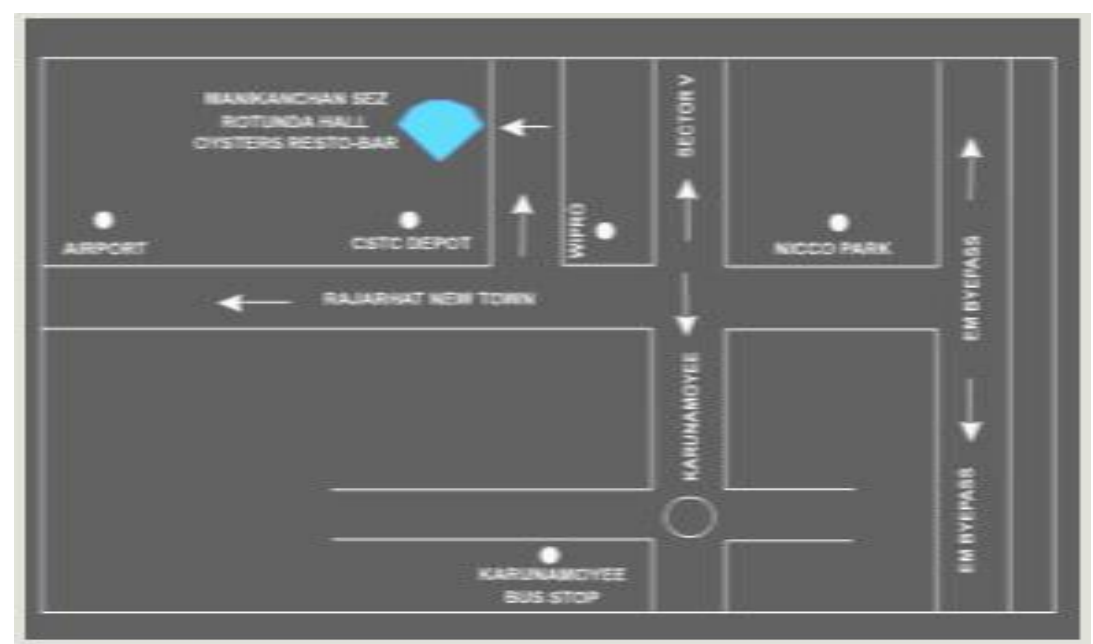

Fig 1: Manikanchan SEZ, Rajarhat, Kolkata [Source: www.wbidc.com]

Manikanchan enjoys a foreign territory status and a duty free zone. The SEZ accrues large locational advantage since it is situated on 
the Rajarhat By-pass in Salt Lake Sector V, also strategically connected via two different highways, only $12 \mathrm{~km}$ away from the Kolkata International Airport. The main purpose of establishing this SEZ was to promote exports. The SEZ recruits skilled artisans in a formal set up by providing them all social security arrangements.

Domjur Growth Pole: Domjur in Howrah has appeared as a separate location for long years back with its high product and labour market linkage with Bowbazar. The market is well-known for producing gold jewelleries with diamond setting and brass metal jewelleries. The production orders come from the contractors of Bowbazar or from the local customers which often get a finishing touch by skilled workers of Bowbazar and

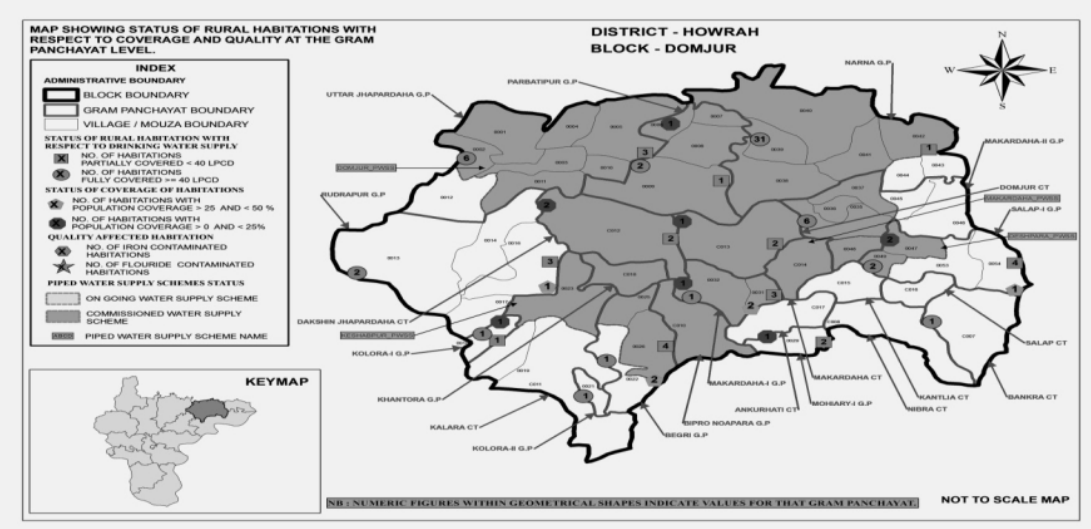

Fig2: Domjur Growth Pole, Howrah

are ready for sale. The diamonds required for production is being imported, the raw gold is supplied by the contractor and other raw materials are purchased by the producer mainly from the local market. In the labour market, majority of the labourers come from the districts of Howrah, Hooghly and West Midnapore. The labourers get training in Howrah and acquire skills and experiences necessary to enter in Kolkata skilled labour market to earn higher wages. They also move to other cities of the country and even to middle-east Asian countries for higher income earnings. 


\section{The Theoretical Argumentation for Growth Polein Domjur}

The theories on location economics refers that industrial clusters do not develop arbitrarily. There are significant economic factors that influence formation of a cluster of industries and businesses in particular spaces. In other sense, the theories explore the logic and science behind: why certain industries emerge and grow in specific geographical locations and why not in others. It may be referred that the enterprises in one location within a cluster with repeated transactions among themselves promote better coordination, trust, informal organizational linkage between enterprises, efficiency, effectiveness, flexibility, formal management linkages in partnerships and alliances, and many others. All these promote sustained spatial bonding among the production units and businesses within a specific geographical location. However, it is not a very good explanation for successful localized industry formation, as is the case of Domjur. In this section, our study attempts to focus on the factors influencing cluster Gems and Jewellery industry formation in Domjur. The factors cited are derived from the classical and neo-classical school of Location Economics literature.

The Support from Classical Literature: To examine the issue on the basis of literature support, we may start with Alfred Marshall (1890, 1892), one of the early contributors in the literature of location economics.vii In his 'Principles of Economics', Alfred Marshall (1891) has referred the idea of "industrial district" that may be appeared as a good explanation for localized industry formation in Domjur.viii To refer Marshall, one of the chief causes behind formation of this particular localized industry in Domjur is rather the "patronage of a court" factor. The richer people assembled there to make a demand for ornaments of especially high quality, which attracted skilled jewelleryworkers from distance areas (East and West Midnapore, Hooghly, and the hinterland of Howrah district). In such a localized industry, workers seek employment where they expect to find a good market for their skill (allowing factor in-mobility) - which happened in Domjur. For these, firms attempted to settle down there. 
Once a localized industry is developed due to functioning of the above-mentioned factor, trading functions of the city are developed. Then it becomes almost stochastic that rent becomes higher in the central sites of a large town or city. This makes the factories 'congregate' in the outskirts of large towns and in their neighbourhood rather than in the towns themselves with physical availability of raw materials. For the same instance, the industry of Domjur has expanded in the peripheral areas of Baruipara, Rudrapur, Kolra, Makardaha, and many others. To Marshall, this "primitive localization" of the industry is transformed into almost an "industrial district" in the long run - hence horizontal expansion and growth of the localized industry has appeared by finding new physical locations even.

In an 'industrial district', "the mysteries of the trade become no mysteries"; and "children learn many of them unconsciously", as Marshall points out. The factor has become strong in case of Domjur (and Ghatal in West Midnapore) than any other spatial cluster of the industry in West Bengal. This is why specialized abilities has been transmittedfrom one generation to another form their teen age and has become an important characteristic of that area. In this way, skills are embodied within one from his/her childhood or teen-age in Domjur - he/she may become unconscious regarding incorporation of this skill within him/her from the childhood, however, may possess some specialized skill after a particular age (usually teen age). Since it has appeared for majority of the people of the area, the area has become renowned for specialized skill and knowledge in jewellery production and has acted upon as an important determinant for concentration of firms requiring this hereditary skill in production.

With specialized skills, high division of labour has appeared with differentiated skill possession by individuals with differentiated abilities that has led to product specialization (particularly of diamond setting in Domjur) and innovation with labour-intensive techniques of production - the 'karigars' of Domjur (and Ghatal) are much renowned throughout the country for their innovativeness. The reason may be found on the fact: in an "industrial district", good ideas are promptly adopted into the production process because good ideas are in the "air" of the district, which works well 
into the well-established social networks with well-developed bonding and tie-ups at the local level - which is strong in Domjur (and Ghatal). In this way, this localized industry of Gems and Jewelleryhas offered "a constant market for skill", particularly when the production of the "industrial district" is skill-based. The employers are assured with supply of skilled workers since there is always a supply of skill in the local market.

With the concentration of a large number of producing firms in a particular area, an industrial atmosphere has built in there. The producing firms have accepted this business stimulus and made faster expansion and growth of the existing localized industry. The industrial leadership has been captured by those firms who are able to initiate or follow these changes appearing in the market. To Scitovsky(1954), in such an atmosphere, the Marshallian "information spillover" affects firm's production function. The "pure" external economies appear due to Marshallian "local market for specialized inputs" and "labour market pooling", which is consistent with imperfect competition with some market power of influential local producers, required for internal economies.ix This has happened in Domjur.

Simultaneously, we may quote some important contributions in the literature i.e. the "Central Place Theory" by Walter Christaller (1933) and August Losch (1944a, 1954b). The major contribution ofChristaller is to show that a hierarchical urban system may exist with a variety of different-sized spatial market areas. ${ }^{x}$ However, the Central Place Theory has been revised latter by Losch. To Losch, any spatial economy would tend to be dominated by a central primal city, the hinterland of which would be characterized by smaller settlements and alternating areas of industrial concentration and dispersion. This Loschian approach has acted as a strong factor to spread the localized industry of the central site of Domjur to its hinterland by making the region almost an "industrial district" through smaller settlements and alterations.

Much later, Becattini $(1989,1990)$ has raised the issue that government and/or government-sponsored institutions are not able to create an industrial organization with collective efficiency rather a minimum concentration of privately initiated industrial activity may involve.xiThis has happened in Domjur where 
privately initiated informal industrial activity has settled down. However, in 2006, the Central Government in its "Growth Pole" programme has included Domjur and Panchla of Howrah among the six selected growth poles throughout the country. In 2011-12, the State Government has initiated an infrastructural development programme to promote growth of the existing cluster of Domjur. These two have approached a government-ledindustrial expansion proposal but that will follow suit only the existing privately initiated industrial activity of the area.

The New Economic Geography Literature: The factors behind Domjur localized industry formation may be searched for with the arguments given by Krugman. Paul Krugman (1991), one important contributor among the new growth theorists, refers that the geographical structure of any (industrial) economy depends on some key parameters. These are: (1) Transportation costs, (2) Economies of scale, and (3) Factor mobility. To Krugman, a combination of these factors results in increasing returns at the production unit. Reduced transport costs provide incentives to locate plants close to large markets. Labour mobility becomes then easier and a regular phenomenon due to the presence of welldeveloped transport and communication in the large markets labour mobility appears from the "traditional" sector considering labour-intensive traditional methods of production to the "modern" sector which employs modern and improved technologies.

A circular causation of all these appears there.xii It provides maximum individual interaction in the informal industrial periphery from the industrial 'core'. The functioning of the "spread effects" accrued from the 'core' growth poles eventually impedes development of the periphery areas through multiplier effect on employment and output and a "relay" function appears through urban hierarchy at the peripheries. This creates an incentive among the producers to form localized industries which may change the spatial production pattern dramatically.

In case of informal agglomeration of the Gems and Jewellery industry inDomjur, the transport cost factor of Krugman does not appear to be crucial. Moreover, labour mobility from the "traditional" sector to the "modern" sector does not become 
compatible in absence of modern mechanized firms. However, maximum individual interaction in the informal industrial periphery of adjacent areas from the industrial 'core' of the main site of Domjur has successfully attributed positive knowledge externality, hence economies of scale appears into. Moreover, labour mobility has provided significant contribution to form the cluster in the presence of effective social capital network. This knowledge spillover and knowledge externality has appeared due to four factors: (1) Marshallian labour market pooling; (2) Pecuniary externalities; (3) Variety of non-traded inputs supplied at the local level; and (4) Information spillovers both in product and labour market processes. Here, the Marshall-Arrow-Romer (MAR)externality suggests that an increased concentration of a particular industry (or service) within a specific geographical region facilitates knowledge spillovers across firms, thereby promotes incentives to innovative activity and inter-firm spillovers. ${ }^{\text {iii }}$

To analyze factor mobility, it is to refer here that the informal worker of Domjur enters into the local job market not with any physical or financial capital but with a social capital xiv that is nothing but a reference (even often oral) by any of his senior experienced community member(s) who is/are already established in the market. However, a mere social capital coverage and informal form of bonding become insufficient to tie up (skill) labour at a particular place since a skilled informal labourer has always a tendency to flow across spaces in absence of much paper works. The already 'settled' migrants work as the 'bridgeheads', form higher expectation about higher standard of living at destination, provide necessary information-remittance-feedbacktraining (even accommodation), and supply necessary social capital required to the newly migrants at their workplace. In this way, they reduce material-psychological costs and risks of spatial migration by formation of a 'migrant community'. Such migration 'networks' $x v$ are renowned in Domjur from where migration has become almost systematic by following a particular pattern or system (the 'system migration'xvi).

Higher is the skill and access to social capital network, higher is the probability for inter-state and international migration, thereby 
higher income earnings. This approaches a 'stochastic' pattern of skill-deterministic labour mobility from Domjur. Such a spatially migrant labour, particularly at the international level, earns much higher income. This higher income, saving, contacts, and long years' experience they invest after spending 10-20 years at destination and become small independent entrepreneurs when they return back to their origin at Domjur. In this way, a vertical (hierarchical) labour mobility appears there which is strong in Domjur.In this, the previously labourer works as individual entrepreneur by attracting a pool of investment and employment at the local level. This particular factor has acted as an influential factor to make spread of peripheries to the hinterland of Domjur in the past two and half decades. The effect is so strong that Domjur is appearing almost an independent spatial cluster in the map of Bengal Gems and Jewellery industry - now Domjur refers weak product market linkage with Bowbazar than before.

The core-periphery model of Venables (1996) starts working herewith - which assumes that mobile workers spend their income at destination. This has caused a circular causation in locational decisions at destination - which has acted as a strong influential factor to form this growing localized industry in Domjur. The mobile workers have preferred to start small businesses in Domjur. This immobility of income at destination has executed the Home Market Effect (HME) by which the geographically concentrated industry has generated an additional demand for the products, particularly in the peripheries of large urban locations in the Howrah district. This has attracted a large number of imperfectly competitive firms towards the large market of the region -the large firms of the industry now have started to open their branches even in Howrah besides Kolkata.

\section{The Argumentfor Special Economic Zonein Manikanchan}

What is true for Domjur is not appearing for Manikanchan. In the Manikanchan SEZ, production is promoted by WBIDC (West Bengal Industrial Development Corporation). The production is carried out totally under the formal sector. The operators are Senco Gold, Shree Ganesh, Rohit Export, Zenith International, Suman Jewelry, FarinniJewellery Private Limited, Mizan\& Company, 
Exotica International and The Ray Incorporated. The operational and promotional costs are primarily borne by the WBIDC, ensuring high level of profitability for the producers. The raw gold is mainly imported from Switzerland, apart from some local market procurements. The formal producers of Manikanchan are free to choose their own production methods and labour. They have the freedom to produce outside the SEZ set up and may have individual local market sales outside. However, no production appears for local market sale within the Manikanchan set up. Within Manikanchan, production is solely carried out for exports in order to achieve the objective of export promotion. In its phase II planning, WBIDC is going to allow selected private partnership under the PPP model.

One crucial factor behind the formation of the SEZ is the provision of regular employment opportunities with formal wage structure covered by social protection measures to the skilled craftsmen of the industry, thereby reducing excessive out-migration to other states. The labourers working in Manikanchan are both local craftsmen and migrant labourers who are paid in accordance with the Labour Laws and Regulations by the Government of India. The labour composition varies with the need of the production units operating within the SEZ.

Another important force behind the formation of the SEZ is export promotion. The production within the SEZ is carried out for exports only. The significance of Manikanchan SEZ to the Bengal Gems and Jewellery industry may be attributed to the fact that about 12 per cent of total exports of Indian Gems and Jewellery industry in 2010-11 has come from Manikanchan. The exports from Manikanchan appear mostly to the Arabian countries, Singapore, Hong Kong, UK and others. Table 1 shows the export experience of Manikanchan in recent times. 
Table 1: Export Figures :- (Rs. Cr.)

\begin{tabular}{||l||c||c||c||c||c||c||c||c||c||}
\hline Month & $\begin{array}{c}2006- \\
07\end{array}$ & $\begin{array}{c}2007- \\
08\end{array}$ & $\begin{array}{c}2008- \\
09\end{array}$ & $\begin{array}{c}2009- \\
10\end{array}$ & $\begin{array}{c}2010- \\
11\end{array}$ & $\begin{array}{c}2011- \\
12\end{array}$ & $\begin{array}{c}2012- \\
13\end{array}$ & $\begin{array}{c}2013- \\
14\end{array}$ & $2014-15$ \\
\hline \hline Apr & 60.16 & 99.10 & 264.71 & 171.77 & 367.34 & 387.28 & 560.21 & 553.96 & 77.13 \\
\hline \hline May & 52.61 & 114.88 & 291.20 & 232.88 & 395.00 & 924.98 & 542.89 & 756.43 & 77.68 \\
\hline \hline Jun & 79.43 & 106.35 & 372.04 & 292.98 & 419.45 & 1538.16 & 1044.12 & 950.47 & 88.87 \\
\hline \hline July & 63.69 & 119.05 & 312.13 & 344.92 & 559.63 & 1145.84 & 567.18 & 764.09 & 60.60 \\
\hline \hline Aug & 73.47 & 126.29 & 292.42 & 250.98 & 616.58 & 646.83 & 611.82 & 764.09 & 316.64 \\
\hline Sep & 60.17 & 108.11 & 309.47 & 314.24 & 412.59 & 1076.44 & 966.87 & 1775.00 & 102.13 \\
\hline \hline Oct & 83.57 & 149.24 & 193.06 & 233.81 & 406.89 & 784.27 & 744.82 & 1558.76 & 63.89 \\
\hline \hline Nov & 82.55 & 128.93 & 211.27 & 286.24 & 333.11 & 1132.18 & 1104.52 & 722.96 & 55.94 \\
\hline \hline Dec & 89.36 & 152.03 & 206.33 & 504.66 & 431.74 & 940.71 & 938.45 & 207.11 & 80.96 \\
\hline \hline Jan & 80.86 & 198.15 & 157.70 & 391.36 & 391.65 & 610.85 & 769.37 & 245.59 & - \\
\hline \hline Feb & 104.96 & 214.82 & 158.49 & 412.69 & 940.44 & 352.31 & 621.65 & 77.82 & - \\
\hline \hline Mar & 187.64 & 258.01 & 212.85 & 452.24 & 2861.35 & 888.86 & 904.87 & 94.81 & - \\
\hline Total & 1018.4 & 1774.9 & 2981.6 & 3888.7 & 8125.66 & $10,428$. & 9376.77 & 8471.09 & 0923.84 \\
\hline
\end{tabular}

Source: www.wbidc.com

For these, Manikanchan resemble with strong economies of scale advantage, following Krugman. The 'Patronage of a court' factor by Marshall also bears significant contribution to Manikanchan due to its operational position within Kolkata. The argument of transport cost advantage by Marshall and Krugman bear significant resemblance in case of Manikanchan due to its strong locational advantage with well-developed transport and communication facilities. Since skilled artisans with formal security arrangements are recruited in Manikanchan, the labour mobility argument of Krugman does not bear any significant bearing in case of Manikanchan as is the case of Domjur. However, the Big Push argument by Rosenstein-Rodan (1943) appears to be sounder in which the solution to the insufficient size of the local market is referred to a co-ordinated government-led expansion of investment, as accrued by the Manikanchan SEZ. This also enables the operating firms to reap the benefits of economies of scale, thereby promoting industrialization. The idea of cumulative causation of Gunnar Myrdal (1957) works herewith - which opines 
that a positive external economies of scale due to localized spillovers makes the location an attractive place to invest.

However, the recent export performance of the Manikanchan SEZ does not reflect the place an attractive place to invest despite the fact that Manikanchan accrue the advantage of Special Economic Zoneto reap the benefits of economies of scale, 'patronage of a court', transport cost advantage, cumulative causation, and big push effect. This raises the question regarding the main objective behind its formation, i.e. of export promotion. The absence of labour mobility with regular wages and formal security arrangements for the recruited labourers appears to be a crucial factor to hinder growth of this formal sector cluster.

Though the trend of dissatisfactory performance of export figures may be a short-term phenomenon and it may be the case that Manikanchan is reviving in near future - however, it has already raised several questions regarding the formation of the SEZ. The issue becomes more crucial when we execute the case of 'Growth Pole' of Domjur Gems and Jewellery industry simultaneously since the performance of Domjuris more than satisfactory in terms of its increasing growth, pooling of investment, and employment generation. Here lies the question whether private initiated informal sector oriented production of the Gems and Jewellery industry is more suitable than the production under governmentsponsored SEZ.

\section{Conclusion}

To analyze the issue examined in the present paper, the existing trends of the Gems and Jewellery industry in West Bengal refers that a private initiated informal sector oriented production is more suitable than a government sponsored formal sector production. The instances of Domjur Growth Pole and Manikanchan SEZ strongly defend the fact. While the growing localized industry of Domjur is successfully extracting positive influences of the factors of transport cost advantage, 'patronage of a court', economies of scale, and factor mobility - the absence of factor mobility is accruing serious obstacles for Manikanchan to reap the desired benefits. Here, the Becattini argument that government and/or 
government-sponsored (formal) institutions are not able to create a successful industrial organization with collective efficiency, rather a minimum concentration of privately initiated (informal) industrial activity may be involved, seems to be more relevant.

\section{Acknowledgement}

I acknowledge to my students of several institutions for their sincere support and participation at the time of data collection procedure during my field survey.

\section{References}

Balwin, R., Forslid, R., Martin, P., \& Robert, N. F. (2003). The core Periphery Model :Key feature and effects. Public Policy and Economic Geography , 213-235.

Brulhart, M. (1998). Economic Geography Location and Trade: The evidence. The World Economy .

Fujita, M. (1989). Urban Economic Theory: Land use and city size. Cambridge: Cambridge University Press.

Fujita, M., Krugman, P., \& Venables, A. (1999). The Spartial Economy: Cities ,Regions and International Trade. Cambridge: Cambridge International Press.

Gayer, H. S. (2002). International Handbook of urban systems :Studies of urbanization and migration in advanced and developing countries. Cheltenham :Edward Ellagar.

Handerson, E. L., \& Thisse, J. F. (2004). Handbook of regional and urban economics. Amsterdam: Elsevier.

Huriot, J. \&. (2000). Economies of cities : Theoretical Prespective . Cambridge: Cambridge University Press.

Krugman, P. (1991). Geography and Trade. Cambridge: MIT Press.

Krugman, P. (2010). The new Economic Geography: Now middleaged. The Association of American Geographers, (pp. 1-19).

Marshall, A. (1890). Principles of Economics. London: MacMillian.

McCann, P. (2007). Urban and Regional Economics. New York: Oxford University Press. 
Rosenthal, S. S., \& Strange, W. C. (2003). Geography , Industrial, Organisation and Agglomeration. Review of Economics and Statistics , 377-393.

Saha, S. (2015). An informal industrial district syntax : From Marshall to Krugman. Splint International Journal of Professional, 2 (5), 17-23.

Saha, S. (2015). In search of effective instruments to tie up skill: An informal industry argument. Desh Vikas , 1 (2), 219-227.

Saha, S. (2015). Localized informal agglomeration : A classical syntax. Desh Vikas , 129-136.

Saha, S. (2015). Sticky Knowlwdge Externity: An instrument to access inovation. International Journal of Inovative Research and Development , 4 (2), 54-60.

${ }^{i}$ Cluster of enterprises is a geographical concentration of micro, small, medium and large enterprises producing same or similar type of goods and services.

ii The important spatial clusters of Gems and Jewellery industry in West Bengal are: Bowbazar (Central Kolkata), Sinthi (North Kolkata), Elgin Road (South Kolkata), Manikanchan (Rajarhat, Kolkata), Domjur (Howrah), Srirampore (Hooghly), Barasat-Basirhat (North 24 Paraganas), Ranaghat (Nadia), Krishnagar (Murshidabad) and Siliguri (North Bengal).

iii The concept of economic growth pole was introduced by French economist Francois Perroux (1949). The idea is based on external economies of scale, agglomeration of small scale industries, and linkage effect. The concept states that a combination of these three at a particular geographical space is sufficient to make an area a growth pole to the region (or district).

iv The term 'agglomeration' of firms refers to decline in average costs in production as more production occurs within a specified geographic area [Anas, Arnott and Small 1998]. In other words, it relies strongly on increasing returns to scale, considering internal and external economies of scale.

v. As referred by Brulhart (1998), while concentration analyzes location across space of a few well-defined sectors, agglomeration analyzes location across space for a larger part of economic activity, and specialization deals with share of a particular location in specific industry in comparison to share of other locations in that industry. 
vi. In its basic essence, Location Economics attempts to study economic organization of a region and between regions. In this sense, Location Economics relates to the study of Regional Economics.

vii. The analysis of location started much before than Marshall with 'monocentric city model' of Von Thunen (1826) [Von Thunen's "Der IsolierteStaat in Beziehung aufLandschaft und Nationalokonomie"].

viii. To Marshall, an "industrial district" means an area (a district) where concentration of firms has settled down in a particular industry or in a group of industries (the 'growth pole'). However, the idea of "industrial district" does not simply refer to a "localized industry" but the idea refers more than it. Usuallya "localized industry" is an industry concentrated in certain geographical spaces. But an "industrial district" refers concentration of firms in an industry (or a group of industries) has settled down.

ix To Scitovsky(1954), incorporation of imperfect competition initiates internal economies of scale that implies market power. Scitovsky distinguishes between "pure" (technological) and "pecuniary" external economies. The former affects firm's production function (e.g. Marshallian "information spillover").

$x$. The Christaller model of central place is, however, inductive rather than deductive in the sense that the model is primarily based on observations rather than exploration of any schema constructed from first principles. To Parr (2002), the Loschian approach is completely deductive and a microeconomic foundation has been approached to understand the urban system. It shows that industrial concentration and urbanization may arise independently of local peculiarity and particularity.

xi. In the Big Push theory (Rosenstein-Rodan, 1943), the solution to the insufficient size of the local market is referred to a co-ordinated (government-led) expansion of investment - hence big push enters into. This enables firms to reap the benefits of economies of scale, thereby promoting industrialization of a backward region. Without such a big push, the backward periphery cannot catch up with the core.

xii. In 1957, Gunnar Myrdal introduced the concept of circular or cumulative causation. In this, once a region (or country) takes lead in the process of economic development, positive external economies of scale in the region (or country) appears there - which ensures that the location will become an attractive place to invest and more attractive location for the labourers to work. The existence of strong localized spillovers leads to the establishment of a core in the region with large market and a periphery [Dicken and Lloyd 1990]. 
xiii. However, Jacobs externality and Porter externality suggest that local competition is suitable to extract knowledge externality.

xiv. Social capital is social organizations (such as trust, norms, reciprocity, co-ordination, interactions belongingness and networks) between producers and workers that facilitate better co-ordinated actions.

xv. Ref: Djajic, 1986; Appleyard, 1992; Massey et al, 1993; Bocker, 1994; Waldorf, 1998; Levitt, 1998; Massey, 1999; Taylor, 1999; De Haas, 2003.

xvi. Ref: Mabogunje, 1970; Arizpe, 1981; Borcocz, 1987; Portes\&Borcoz, 1987; McKee \&Tisdell, 1988; Fawcett, 1989; Massey, 1990; Kritz et al, 1992;

Martin, 1992; Gurak\&Caces, 1992; Bohning, 1994; Martin \& Taylor, 1996; Rotte et al, 1997; Vertovec, 1999; Olesen, 2002; van Dalen et al, 2005. 